\title{
Güneş Enerjili Kurutucuda Kurutulan Elma Dilimlerinin Kurutma Koşullarının RSM ile Optimizasyonu
}

\author{
Zehra YILDIZ ${ }^{1 *}$ \\ Leyla GÖKAYAZ ${ }^{2}$
}

\begin{abstract}
Özet
Taze gıda ürünlerinin, uzun süre bozulmadan depolanması için çeşitli kurutma teknikleri bulunmaktadır. Bunlar arasında sıcak hava ile kurutma, vakumda kurutma, güneş kolektörleri yardımıyla kurutma, mikrodalga kurutma ve dondurarak kurutma gibi yöntemler sayılabilir. İşlemlerin ekonomik ve ürün kalitesinin yüksek olması için optimizasyon önemli bir işlemdir. Bu sebeple çalışmada, çok raflı güneş enerjili kurutucu ile elma kurutulmuş ve kurutma koşulları Yanıt Yüzey Yöntemi ile optimize edilmiş̧ir. Yanıt Yüzey Yönteminde kurutma parametreleri, dilim kalınlı̆̆ı, kurutma süresi ve tepsiye yüklenen elma dilimlerinin kütlesi olarak seçilmiştir. Optimize edilen yanıt ise kurutma hızı, \% nem kayb1 ve büzülme oranı olarak seçilmiştir. Üç faktörlü merkezi kompozit dizayn (CCRD) ile kurutma süresi $(58.6-361 \mathrm{dk})$, tepsiye yüklenen elma dilimlerinin kütlesi (32.7-167 g) ve elma dilim kalınlığı (3.98-9.02 mm) aralığında uygulanmıştır. Elde edilen veriler ANOVA ile analiz edilmiş ve ikinci derece bir polinom model belirlenmiştir. Bu modelin analitik çözümünden optimum kurutma parametreleri bulunmuştur. Maksimum nem kaybı ve büzülme oranı minimum kuruma hızı için kurutma süresi (159$274 \mathrm{dk}$ ), tepsiye yüklenen elma dilimlerinin kütlesi (92.86-105.72 g) ve elma dilim kalınlığı (6.48-6.667 $\mathrm{mm}$ ) bulunmuştur.
\end{abstract}

Anahtar kelimeler: Kurutma, Güneş enerjili kurutucu, Elma, RSM

\section{Optimization with RSM of Drying Conditions of Dried Apple Slices in Solar Dryer}

\begin{abstract}
There are various drying techniques for long-term storage of fresh food products. These include hot air drying, vacuum drying, drying with solar collectors, microwave drying and freeze drying. Optimization is an important process for the economic and product quality of the processes. For this reason, in the study, the apple was dried with multi-rack solar power dryer and the drying conditions were optimized with Response Surface Method. In the Response Surface Method, the drying parameters were selected as slice thickness, drying time and fresh matter amount. The response to be optimized was chosen as drying rate, moisture loss and shrinkage rate. The three-factor central composite design (CCRD) was applied to the drying time (58.6-361min), the amount of substance $(32.7-167 \mathrm{~g})$ and the apple slice thickness $(3.98-9.02 \mathrm{~mm})$. The data were analyzed by ANOVA and a second order polynomial model was determined. Optimum drying parameters were found from the analytical solution of this model. The maximum moisture loss and shrinkage rate were determined as drying time (159-274 minutes), amount of material (92.86-105.72g) and apple slice thickness (6.48$6.667 \mathrm{~mm}$ ) for minimum drying rate
\end{abstract}

Keywords: Drying, Solar dryer, apple, RSM

ORCID ID (Yazar sirasina göre)

0000-0003-1304-4857, 0000-0002-7580-9838

\footnotetext{
Yayın Kuruluna Geliş Tarihi:19.03.2019

Kabul Tarihi:17.12.2019

${ }^{*}$ Tarsus Üniversitesi, Teknoloji Fakültesi, Enerji Sistemleri Mühendisliği Bölümü, Mersin

${ }^{2}$ Tarsus Üniversitesi, Lisansüstü Eğitim Enstitüsü, İmalat Mühendisliği Anabilim Dalı, Mersin

E-mail: zyildiz@tarsus.edu.tr
} 


\section{Güneş Enerjili Kurutucuda Kurutulan Elma Dilimlerinin Kurutma Koşullarının RSM ile Optimizasyonu}

\section{Giriş}

Güneş 1şııımının yüksek olduğu ülkelerde, ürünlerin günește kurutulması oldukça yaygin kullanilan bir gida koruma yöntemidir. Büyüyen nüfusa sürekli gıda tedarikinin sağlanması ve çiftçilerin kaliteli pazarlanabilir ürünler üretmesi için hem verimli hem de uygun fiyatl1 kurutma yöntemleri gereklidir. Bugün dünya üzerinde pek çok ülkede ürünler direkt güneş altında bırakılarak eski metotlarla kurutma yapılmaktadır. Ancak, bu yöntemin enerji sarfiyatı olmasa da pek çok dezavantajı vardır. Kurutulacak ürün atmosfere açık ortamda kurutulduğu için ürün dıșarıdan gelebilecek istenmeyen bazı safsızlıklarla kirlenerek kuru ürün kalitesini olumsuz etkilenebilir. $\mathrm{Bu}$ kurutma yöntemi yazın güneşli zamanlarda ve geniş alanlarda yapılmaktadır. Kurutulacak ürün alana serilip, uzun sürelerde kuruyana kadar güneş altında bekletilir. Ancak yağmur yağdı ̆̆ zaman ürün 1slanıp, üründe yeniden kurutma ihtiyacının doğması ve kurutulmuş ürünün tekrar nem alarak kalite özelliklerini yitirmesi bu yöntemin başlıca olumsuzlukları arasında gösterilebilir. Bu olumsuz etkileri ortadan kaldırmak için çeşitli kurutucular kullanılabilir ancak güneş enerjili kurutucular dışındaki kurutucular konvansiyonel enerji kaynakları ile çalışmakta olup, hem çevre hem de işletme maliyeti açısından uygun olmamaktadır. Türkiye ve Mersin'de üretiminin fazla olduğu elmanın kurutma sıcaklığı ve elmadan uzaklaştırılması gereken nem içeriğine bakıldığında güneş enerjili kurutucuların kullanımının fayda sağlayacağ1 görülmektedir. Elma, çok üretilen ve tüketilen, yaz kış daima bulunabilen bir meyve olup, en az başlangıç neminin \%60'1 uzaklaştırılması ve kurutma sicaklığının $74 \mathrm{oC}$ üzerinde olmas1 sebebiyle bir kurutucuda kurutulmasıyla kaliteli ve raf ömrü uzun bir kuru ürün elde edilebileceğinden seçilmiştir (Ertekin ve Yaldız, 1998). Güneş enerjili kurutucuların enerjiyi güneşten aldığ 1 için yakıt masrafı yoktur dolayısıyla daha ekonomiktir. Aynı zamanda daha temiz, daha kısa sürede ve düşük sıcaklıkta kuru ürün elde etmek için önemli avantajlar sağlar (Oztürk, 2008: Aktas ve ark., 2006: Yildiz ve Gokayaz 2015). Mersin ili y1lın 300 günü güneș alan, güneş enerjisi bakımından birinci kuşakta yer alan güneşlenme potansiyeli oldukça yüksek olan bir ilimizdir. Hem güneşlenme potansiyeli hem de yaş sebze ve meyve üretiminde önde gelen bir il olması sebebiyle güneşin 1sıtma etkisinden gıda alanında kurutma işleminde faydalanarak ve bu kurutma işleminin optimizasyonu yapılarak ülkenin tarımgida ekonomisine önemli katk1 sağlanabilir. Kurutma parametreleri optimize edilerek güneş enerjili kurutucuların kullanımının sanayide uygulanabilirliği arttırılarak yaygınlaşması sağlanabilir. Optimizasyon yöntemleri, proses tasarımlarını verimli bir hale getirmek amaciyla uygulanmaktadır. Kurutma işleminin optimizasyonu için gıda kurutma işlemlerinin optimizasyonunda çok sık kullanılan, daha az sayıda deney ile optimum sonuca ulașılabileceğimiz Yanıt Yüzey Yöntemi kullanılmıştır. Yanıt Yüzey Yönteminde kurutma parametreleri, dilim kalınlığ 1 , kurutma süresi ve tepsiye yüklenen elma dilimlerinin kütlesi, olarak seçilmiştir. Optimize edilen yanıt ise kurutma hızı, \% nem kaybı ve büzülme oranı seçilmiştir. Yanıt yüzey yöntemi ile kurutma parametreleri ve yanitlar arasinda uygun bir matematiksel model elde edilmiş, bu model üzerinden optimum kurutma parametreleri bulunmuş, değişkenlerin yanıt üzerindeki etkisi belirlenmiştir.

\section{Materyal ve Metot}

$\mathrm{Bu}$ çalışma kapsamında elma kurutmada kullanılacak olan çok raflı doğal konvektif güneş enerjili kurutucu özel olarak tasarlanmıştır. Şekil 1'de gösterilen kurutucu; kolektör (toplayıc1), kurutma bölmesi (odası) ve bacadan oluşmaktadır. Kurutucu odası içerisinde raflar yerleştirilmiştir. Arka cephede rafların kurutucu içine yerleştirilebilmesi için bir kapak bulunmaktadır. Kolektör ile güneş 1şınımları tutularak 1sı enerjisine çevrilir ve kurutma havasına aktarılır. Güneş 
kolektöründe güneş 1şınları absorbe edilip, kolektör içerisine alınan hava 1sınır veısınan hava kurutma odasina girer; raflar halinde yerleştirilmiş ve elma bulunan kurutma raflardan geçerek ürünün nemini alır ve ürünlerin yerleştirildiği delikli raflardan geçerek her iki yüzeyde yer alan hava çıkış açıklıklarından nemli hava kurutucu dışına atılarak kurutma işlemi tamamlanır.

Güneş enerjisi ile 1sıtılan hava yardımıyla alınan meyve veya sebzenin nemi, yine ayn ortamından uzaklaştırılmaktadır.

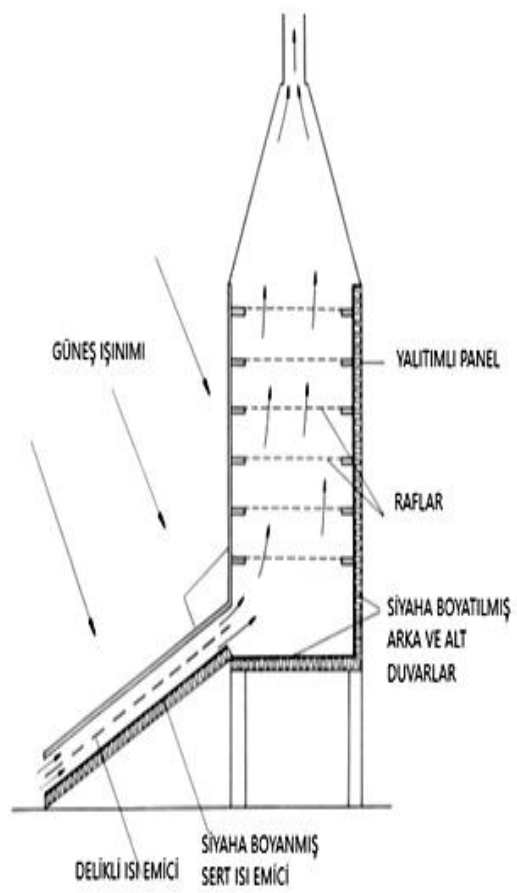

Şekil 1. Çok Raflı Doğal Konvektif Güneş Enerjili Kurutucu

Denemeler için Starking Delicious cinsi elma kullanılmıștır. Elmalar denemelerden önce bir takım hazırlı safhalarından geçirilmiştir. Yıkanıp kabukları soyulan elmaların çekirdekleri alınmış ve ardından da ikiye bölünerek yarım ay şeklinde belirlenen dilim kalınlıklarında dilimlenmiştir. Kurutma öncesi ilk ağırlık ölçümleri hassas terazi ile ölçülmüştür. Elma dilimlerinin hacim ölçümleri ise cam mezür ile belirlenmiştir.
Gıdalar hasat sonrasında ve çeşitli işlemlerden geçtiklerinde yapılarında kalitelerini etkileyen birtakım değişimler oluşmaktadır. Elma için de renk değişimi kaliteyi olumsuz etkileyen bir parametredir. Elmanın yapısında bulunan fenolik bileşiklerin, uygulanan işlemler (soyma, dilimleme gibi) sonucunda meydana gelen esmerleşmeyi önlemek için elma dilimleri \%0,3 konsantrasyonundaki sitrik asit çözeltisine batırılmıştır. Çözeltiden alınan dilimlenmiş elmaların fazla suları süzgeçler yardımıyla süzdürülerek kurutma işlemleri için tepsilere yerleştirilmiştir.

Kurutmaya etki eden faktörler olarak kuruma süresi, dilim kalınlığı ve tepsiye yüklenen kütle miktarı seçilmiştir. RSM deki deney tasarımına göre belirlenen kuruma süreleri boyunca ağırlık ve hacim ölçümleri alınmış, \%nem kaybı, kurutma hızı ve büzülme oranları gibi kurutma verileri elde edilmiştir. $\mathrm{Bu}$ veriler aşağıdaki eşitlikler yardımıyla belirlenmiştir (Darıcı ve Şen 2012; Aboud 2013; Tüfekçi 2014).

$$
\begin{aligned}
& \text { Nem Kaybı }=\frac{M_{0}-M_{t}}{M_{0}} \\
& \text { Kuruma Hızı }=\frac{M_{0}-M_{t}}{\Delta t} \\
& \text { Büzülme oranı }=\frac{V_{0}-v_{t}}{V_{0}}
\end{aligned}
$$

Eşitlik 1 ve 2'de yer alan $M_{0}$ ve $M_{t}$ kurutma öncesi elma diliminin ağırlığı ve kurutma sonrası elma diliminin ağırlıklarını (g), eşitlik 3'de yer alan $V_{0}$ ve $V_{t}$, kurutma işleminden önceki örnek hacmi (v0) ve kurutma işlemi sonundaki örnek hacmini (ml) ifade etmektedir. $\Delta \mathrm{t}$, kurutma işleminin süresini ifade etmektedir.

\section{Yanıt Yüzey Yöntemi (RSM)}

Yanıt yüzey yöntemi, problemlerin analizi ve modellenmesinde matematiksel ve istatistiksel yöntemlerin bir arada kullanılarak sonucun optimize edilmesi olarak açiklanmıştır. Prosesi etkileyen parametreler bağımsız değişkenler olarak, yanıtlar ise bağımlı değişkenler olarak 


\section{Güneş Enerjili Kurutucuda Kurutulan Elma Dilimlerinin Kurutma Koşullarının RSM ile Optimizasyonu}

adlandırılmaktadır. Optimum bölge, yanıtların izohips eğrilerinin çizilerek üst üste yerleștirilmesi veya istenilen hedefe ulaşma fonksiyonu veya lineer olmayan programlama yaklaşımları kullanılarak belirlenir. İlk kimya alanında kullanılsa da son yıllarda tıp, ilaç sanayi, gıda sektörü, bilgisayar ve otomotiv sektörleri gibi pek çok uygulama alanı bulmuştur.RSM uygulamalarında ilk olarak bir dizi fikirler öne atılarak sistemi karakterize edebilecek yanitlar ve bunlar üzerinde etkili olabilecek faktörlerin veya değișkenlerin belirlenmesi gerekir. Birçok proseste bu faktörler oldukça fazla olabilir. $\mathrm{Bu}$ gibi durumlarda ön denemeler yapilarak, faktörler arasından istatistiksel olarak en önemli olan birkaç faktör seçilebilir. Bu denemeler eleme denemeleri olarak bilinir ve araştırmanın ilerleyen aşamalarında daha az deneme yapılmasını sağlar. Böylece zaman ve maliyet açısından önemli avantaj sağlanmış olunur.

İkinci aşamada; bağımsız değişkenlerin deneme bölgesinde belirlenen seviyelerin, sistemin yanıtında oluşturdukları değere bakılarak optimum noktaya yakın sonuçlar verip vermediğine bakılır. Oluşturulan yanıt yüzeydeki eğrilik, optimuma yaklaştıkça belirgin hale gelir.RSM'nin üçüncü aşaması optimum noktaya yaklaşıldığında başlar. Araştırmacı burada gerçek yanıt fonksiyonunu doğru ve hassas bir şekilde tahmine çalışır. Gerçek yanıt fonksiyonu, optimum nokta etrafinda önemli bir eğrilik gösterir ve bu eğrinin tahmininin yapılmasında ikinci dereceden modeller kullanılır. Uygun bir model elde edildikten sonra bu model optimum noktanın araştırılmasında kullanılır.

Gida bilimi ve teknolojisi alanında yaygın olarak kullanilan optimizasyon yöntemlerden biri olan RSM, prosesin performansı ve ürünün kalite özellikleri üzerinde çok sayıda proses parametresinin etkili olduğu durumlarda daha sik kullanılmaktadır. RSM, dinamik bir optimizasyon yöntemi olup, sistemin amaç fonksiyonuna etki eden çok sayıda değişkeni bir arada ve eşzamanlı olarak inceler. Kurutma ile yapilan bu çalışmaların çoğunda RSM kullanılmıştır.
Çok raflı güneş enerjili kurutucudaki kurutma işlemin optimizasyonu için yanıt yüzey yöntemi kullanılmış, bu yöntemin belirlediği deneysel tasarıma göre deneyler yapılmış, elde edilen deney sonuçlarına göre matematiksel model elde edilmiş ve bu model üzerinden optimizasyon yapılmıştır (Ertekin ve Sultanoğlu, 2000: Mitra ve Meda, 2009: Eren ve Ertekin, 2007: Eren, 2004: Yıldız ve. Sarımeşeli 2015, 2016)

\section{Sonuçlar ve Tartışma \\ Deneysel Tasarım}

Yanıt yüzey yöntemi analizi için Design Expert 6.0.10 programı kullanılmıştır. Kurutma işleminin parametreleri olan bağımsız giriş değişkenleri dilim kalınlığı, kurutma süresi ve tepsiye yüklenen elma dilimlerinin kütlesi seçilmiştir. $\mathrm{Bu}$ değişkenlerin daha önce yapılan kurutma çalışmalarında belirlenen yanıtlar üzerinde önemli etkisi olduğu görülmüştür. Ayrıca RSM deneysel tasarımında deney koșullarının kolaylıkla ayarlanabileceği ve kontrol edilebileceği değişkenler olduğu için bu parametreler seçilmiştir. Parametre sayısı arttıkça kurulacak matematiksel model kompleks olacak ve model üzerinden yapılacak optimizasyonda güç olacağ1 için yanıtları etkileyen en önemli bu üç kurutma parametresi seçilmiştir. Giriş değişkenlerinin alt-üst sınırları programa belirlenmiş, faktörler ve etki düzeylerine göre program deney seti oluşturulmuştur. Sonuç olarak bu yöntem ile kurutma işleminin giriş parametrelerinin optimum seviyelerinde elde edilecek maksimum yanıtlar arasında kurulacak en uygun matematiksel model seçilmiş, deney sonuçları matematiksel modelle karşılaștırılmıștır. Ayrıca optimum sonuçlar ve kurutma işleminin parametrelerinin deney sonuçları üzerine etkisi belirlenmiştir. Bu çalışma sonucunda elde edilen sonuçlar ANOVA tabloları verilmiştir.

Tablo 1'de verilen deney veri seti, bağımsız değişkenlerden olan $\mathrm{X}_{1}$ tepsiye yüklenen elma dilimlerinin kütlesi (32.7$167 \mathrm{~g}$ ), $X_{2}$ kuruma süresini (58.6- $361 \mathrm{dk}$.) ve $X_{3}$ ise elma dilim kalınlığını (3.98- 9.02 


\section{Güneş Enerjili Kurutucuda Kurutulan Elma Dilimlerinin Kurutma Koşullarının RSM ile Optimizasyonu}

$\mathrm{mm}$ ) ifade etmektedir. Değişkenlerin alt ve üst sinırları daha önce yapılan deneyler sonucunda belirlenmiștir. Elma dilimleri miktarı, dilim kalınlığı ve kurutma süresi için optimal seviyelerin beş farklı kod değerleri $-\alpha,-1,0,1$ ve $+\alpha$ olarak verilmiştir.-1, $\mathrm{X}$ parametresinin minimum kod seviyesi, 0 , X parametresinin ortalama değeri, $+1, \mathrm{X}$ parametresinin maksimum kod seviyesini ifade etmektedir. $-\alpha, \mathrm{X}$ parametresinin minimum değerinin $\alpha$ kadar altındaki kod seviyesini ve $+\alpha, \quad \mathrm{X}$ parametresinin maksimum değerinin $\alpha$ kadar üstündeki kod seviyesini ifade etmektedir. $\alpha$, eksenel parametre için düzeltme terimi olup, aşağıdaki eșitlikteki gibi hesaplanır. $2 \mathrm{k}$ faktöriyel noktalarının sayısıdır. Üç giriş değişkeni için $\alpha=1.68 \mathrm{dir}$ [13].

$$
\alpha=\sqrt[4]{2^{k}}
$$

Tablo 1. Değiş̧kenlerin Gerçek Değerleri ve Kodları

\begin{tabular}{cccccc} 
& \multicolumn{5}{c}{ Kod Seviyeleri } \\
& $-\alpha$ & -1 & 0 & 1 & $+\alpha$ \\
$\mathrm{X}_{1}$ & 32.7 & 60 & 100 & 140 & 167 \\
$\mathrm{X}_{2}$ & 58.6 & 120 & 210 & 300 & 361 \\
$\mathrm{X}_{3}$ & 3.98 & 5.00 & 6.50 & 8.00 & 9.02
\end{tabular}

Tablo 1 de verilen giriş değişkenlerinin altüst sınırları programa yüklenmiş, faktörler ve etki düzeylerine göre program tablo 2 deki deney seti oluşturmuştur. Deney tasarımında, yanıt yüzey yönteminin CCRD (Merkezi Tümleşik Tasarım) (Central Composite Rotatable Tasarım) yöntemi kullanılmıştır. Bu yöntemde her bir faktör için merkez noktadan uzak faktöriyel noktalar için \pm 1 birim, eksen noktaları ise $\pm \alpha$ birimdir. Merkez noktada 6 , eksen noktalarında 6 ve faktöriyel noktalarda ise 8'erolmak üzere toplam 20 deneme içeren bir tasarım oluşturuldu.

Kurutulacak üründen nemin uzaklaştırılması ürünün uzun süre depolanabilmesi ve muhafazası için oldukça önemlidir. Havanın nemi, sıcaklığ 1 ve kurutulacak ürünün dilim kalınlığ kuruma hızını etkilemektir. Bu nedenle yanıtolarak (çıkış değişkenleri) uzaklaştırılan su kaybı (YWL), kuruma hızı (YDR) ve büzülme oranı (YSR) seçilmiştir.

Tablo 2. Deney Veri Seti

\begin{tabular}{|c|c|c|c|c|c|c|}
\hline $\begin{array}{c}\text { Deney } \\
\text { No }\end{array}$ & $\mathrm{X}_{1}$ & $\mathrm{X}_{2}$ & $\mathrm{X}_{3}$ & YwL & $Y_{D R}$ & YSR $_{\mathrm{SR}}$ \\
\hline & $\overline{1.0}$ & - & - & & & \\
\hline 1 & 0 & 1.00 & $\begin{array}{c}1.00 \\
- \\
1.0\end{array}$ & 0.360 & 0.023 & 0.368 \\
\hline 2 & $\begin{array}{c}1.00 \\
- \\
1.0\end{array}$ & -1.00 & $\begin{array}{l}0 \\
- \\
1.0\end{array}$ & 0.451 & 0.026 & 0.476 \\
\hline 3 & 0 & 1.00 & $\begin{array}{l}0 \\
- \\
1.0\end{array}$ & 0.747 & 0.019 & 0.834 \\
\hline 4 & $\begin{array}{c}1.00 \\
- \\
1.0\end{array}$ & 1.00 & 0 & 0.704 & 0.018 & 0.725 \\
\hline 5 & 0 & -1.00 & 1.00 & 0.299 & 0.025 & 0.290 \\
\hline 6 & $\begin{array}{c}1.00 \\
- \\
1.0\end{array}$ & -1.00 & 1.00 & 0.353 & 0.027 & 0.379 \\
\hline 7 & 0 & 1.00 & 1.00 & 0.597 & 0.020 & 0.617 \\
\hline 8 & $\begin{array}{c}1.00 \\
- \\
1.6\end{array}$ & 1.00 & 1.00 & 0.597 & 0.021 & 0.627 \\
\hline 9 & 8 & 0.00 & 0.00 & 0.598 & 0.024 & 0.635 \\
\hline 10 & 1.68 & 0.00 & 0.00 & 0.529 & 0.021 & 0.590 \\
\hline 11 & 0.00 & -1.68 & 0.00 & 0.170 & 0.026 & 0.187 \\
\hline 12 & 0.00 & 1.68 & $\begin{array}{c}0.00 \\
- \\
1.6\end{array}$ & 0.653 & 0.017 & 0.621 \\
\hline 13 & 0.00 & 0.00 & 8 & 0.674 & 0.018 & 0.741 \\
\hline 14 & 0.00 & 0.00 & 1.68 & 0.477 & 0.028 & 0.519 \\
\hline 15 & 0.00 & 0.00 & 0.00 & 0.518 & 0.023 & 0.539 \\
\hline 16 & 0.00 & 0.00 & 0.00 & 0.535 & 0.023 & 0.545 \\
\hline 17 & 0.00 & 0.00 & 0.00 & 0.548 & 0.024 & 0.537 \\
\hline 18 & 0.00 & 0.00 & 0.00 & 0.552 & 0.024 & 0.596 \\
\hline 19 & 0.00 & 0.00 & 0.00 & 0.575 & 0.024 & 0.591 \\
\hline 20 & 0.00 & 0.00 & 0.00 & 0.575 & 0.025 & 0.585 \\
\hline
\end{tabular}

$\mathrm{Y}_{\mathrm{WL}}, \mathrm{Y}_{\mathrm{DR}}$ ve $\mathrm{Y}_{\mathrm{SR}}$ yanıtları için oluşturulan modelin varyans analizi (ANOVA) sonucunda çok küçük bir olasılık değeri (P değeri) alması modelin önemini ortaya koymaktadır. ANOVA. P değerinin 0.0001 'den küçük olduğu yerlerde modelin anlamlı olduğunu ileri sürülmektedir. Katsayıların her birinin önemini kontrol etmek için bir araç olarak kullanılan $\mathrm{P}$ değerleri. değişkenler arasındaki etkileşim şeklini göstermektedir. Değişkenlerin her 


\section{Güneş Enerjili Kurutucuda Kurutulan Elma Dilimlerinin Kurutma Koşullarının RSM ile Optimizasyonu}

bir yanit üzerindeki etkisi ANOVA tabloları ile verilmiştir. $\mathrm{P}$ değerleri. bağımsız değişkenler arasında ortak etkileşimli modelleri tanımlamak için gerekli olan katsayıların önemini vurgulamaktadır. P değeri 0.0001 'den küçük olması modelin önemli olduğunu göstermektedir. Tablo 3'de $\mathrm{P}<0.0001$ 'deki yanttlar için istatistiksel olarak önemli olan bazı değişkenler bulunmaktadır. Belirlenen değişkenlerin nem kaybı. kuruma hızı ve büzülme oranı üzerinde önemli etkileri bulunmaktadır. Her bir cevap için değişkenlerin kodlanmış değerlerine karşılık gelen ikinci dereceden modeller birleștirilmiștir.

En iyi model performansları $\left(\mathrm{R}^{2}\right.$ değerleri nem kaybı için 0.981. kuruma oranı için 0.801 ve büzülme oran1 için ise 0.973 ) lineer, ikinci derece poliminal, çapraz çarpım ve kübik modeller içerisinden en yüksek uyumu $\left(\mathrm{R}^{2}\right)$ veren denklem seçilmiştir.

Tablo 3. RSM için Regresyon Parametrelerinin ANOVA Değeri

\begin{tabular}{llllll}
\hline Yanıt & Regrasyon & $\mathrm{df}$ & $\mathrm{R}^{2}$ & $\mathrm{~F}$ & $\mathrm{P}>\mathrm{F}$ \\
\hline & Doğrusal & 3 & 0.865 & 34.2 & $<0.0001$ \\
& Çapraz- & & & & \\
& çarpım & 3 & 0.880 & 0.529 & 0.670 \\
Kem & $\underline{\text { Kuadratik }}$ & $\underline{3}$ & $\underline{0.981}$ & $\underline{17.9}$ & $\underline{0.000239}$ \\
Kayb1 & Artık & 4 & & & \\
& Toplam & 20 & & & \\
& Doğrusal & $\underline{3}$ & $\underline{0.801}$ & $\underline{21.5}$ & $\underline{\leq 0.0001}$ \\
& Çapraz- & & & & \\
& çarpım & 3 & 0.815 & 0.319 & 0.811 \\
Kurutma & Kuadratik & 3 & 0.872 & 1.50 & 0.274 \\
Hızı & Artık & 4 & 0.989 & & \\
& Toplam & 20 & & & \\
& Doğrusal & 3 & 0.793 & 20.4 & $<0.0001$ \\
& Çapraz- & & & & \\
& çarpım & 3 & 0.826 & 0.815 & 0.508 \\
Büzülme & Kuadratik & $\underline{3}$ & $\underline{0.973}$ & $\underline{17.9}$ & $\underline{0.000243}$ \\
Oranı & Artık & 6 & & & \\
\hline
\end{tabular}

Tablo 2 de görüldüğü üzere $\mathrm{Y}_{\mathrm{WL}}$ olarak gösterilen su kayb1 \%17 ila \%74.7 değerleri arasında iken, $\mathrm{Y}_{\mathrm{DR}}$ olarak verilen kuruma hızı 0.016 ila $0.280 \mathrm{~g} / \mathrm{dk}$ arasında ve $Y_{\mathrm{SR}}$ ile belirtilen büzülme oranı ise 0.187-0.834 değerleri arasında değişmektedir. Su kaybı ve büzülme oranı için maksimum ve minimum değerleri veren deney koşulları aynı olup, maksimum yanıt için 3 nolu deney ve minimum yanıtlar için 11 nolu deney olmuştur. Buna göre, en fazla su kaybı ve büzülme oranı elma dilim kalınlığının 5 mm ve kurutma süresinin 300 dakika olduğu 60 gramlı denemede gözlemlenirken, en düşük su kaybı ve büzülme oran 158.6 dakikada yapılan 6.50 $\mathrm{mm}$ dilim kalınlığındaki 100 gramlık yüklemede gözlemlenmiştir. Kuruma hızı ise elma dilim kalınlığının $9.02 \mathrm{~mm}$ olduğu 100 gram yükleme yapılarak 210 dakikada kurumaya birakılan denemede maksimum değerini ve $6.50 \mathrm{~mm}$ kalınlığında 361 dakika boyunca kurutulan 100 gramlık yükleme yapılan denemede minimum değerine ulaşılmıştır.

Yanıt Yüzey Yönteminin Değerlendirilmesi

Her katsayının ve etkileşimlerinin önemi Tablo 4'de gösterilmiştir. Genel olarak araştırılan özellikler üzerinde yanıtlar üzerinde etkisinin çok önemli olduğu, dilim kalınlığ 1 ve kuruma süresinin özellikle nem kaybını ve büzülme değerlerini önemli derecede $(\mathrm{P}<0.001)$ etkilediği, kurutma hızı üzerine özelikle kuruma süresinin önemli etkisi olduğu $\quad(\mathrm{P}<0.001) \quad$ belirlenmiştir. Tepsiye yüklenen taze elma dilim miktarının ise yanıtlar üzerinde önemli bir etkisi olmadığ 1 görülmüştür.

Tablo 4. Yanıt Modelleri için ANOVA Tabloları

\begin{tabular}{|c|c|c|c|c|}
\hline \multicolumn{5}{|c|}{ Nem Kaybı } \\
\hline Faktör & $\begin{array}{l}\text { Kareler } \\
\text { Toplamı }\end{array}$ & df & $\begin{array}{l}\mathrm{F} \\
\text { Değeri }\end{array}$ & $\begin{array}{l}\text { p-değeri } \\
\text { Olasilik } \\
>\text { F }\end{array}$ \\
\hline Model & $\begin{array}{l}0.376 \\
134 F_{-}\end{array}$ & 9 & 57.9 & $\begin{array}{l}< \\
0.0001\end{array}$ \\
\hline $\mathrm{X}_{1}$ & 005 & 1 & 0.0185 & $\begin{array}{l}0.895 \\
<\end{array}$ \\
\hline $\mathrm{x}_{2}$ & 0.291 & 1 & 403 & $\begin{array}{l}0.0001 \\
<\end{array}$ \\
\hline $\mathrm{x}_{3}$ & $\begin{array}{l}0.0409 \\
0.00027\end{array}$ & 1 & 56.6 & 0.0001 \\
\hline $\mathrm{x}_{1}{ }^{2}$ & 5 & 1 & 0.381 & $\begin{array}{l}0.551 \\
<\end{array}$ \\
\hline $\mathrm{x}_{2}{ }^{2}$ & 0.0353 & 1 & 48.8 & 0.0001 \\
\hline $\mathrm{x}_{3}{ }^{2}$ & 0.00105 & 1 & 1.45 & 0.256 \\
\hline
\end{tabular}




\begin{tabular}{|c|c|c|c|c|}
\hline $\mathrm{x}_{1} \mathrm{X}_{2}$ & 0.00443 & 1 & 6.13 & 0.0328 \\
\hline $\mathrm{x}_{1} \mathrm{X}_{3}$ & $\begin{array}{l}3.69 \mathrm{E}- \\
006\end{array}$ & 1 & 0.00510 & 0.944 \\
\hline $\mathrm{x} 2 \mathrm{X}_{3}$ & 0.00119 & $\begin{array}{l}1 \\
1\end{array}$ & 1.65 & 0.228 \\
\hline $\begin{array}{l}\text { Artık } \\
\text { Model } \\
\text { uygunsuzluğ }\end{array}$ & 0.00723 & 0 & & \\
\hline $\mathrm{u}$ & 0.00471 & 5 & 1.88 & 0.253 \\
\hline Hata & 0.00251 & $\begin{array}{l}5 \\
1\end{array}$ & & \\
\hline Toplam & 0.384 & 9 & & \\
\hline \multicolumn{5}{|c|}{ Büzülme Oranı } \\
\hline Faktör & $\begin{array}{l}\text { Kareler } \\
\text { Toplamı } \\
\end{array}$ & df & $\begin{array}{l}\mathrm{F} \\
\text { Değeri }\end{array}$ & $\begin{array}{l}\text { p-değeri } \\
\text { Olasılık } \\
>\mathrm{F}\end{array}$ \\
\hline Model & $\begin{array}{l}0.434 \\
3.67 \mathrm{E}-\end{array}$ & 3 & 39.4 & $\begin{array}{l}< \\
0.0001\end{array}$ \\
\hline $\mathrm{x}_{1}$ & 005 & 1 & 0.0300 & $\begin{array}{l}0.866 \\
<\end{array}$ \\
\hline $\mathrm{X}_{2}$ & 0.299 & 1 & 244 & $\begin{array}{l}0.0001 \\
<\end{array}$ \\
\hline $\mathrm{x}_{3}$ & 0.0545 & 1 & 44.5 & 0.0001 \\
\hline $\mathrm{X}_{1}^{2}$ & 0.00323 & 1 & 2.64 & $\begin{array}{l}0.135 \\
<\end{array}$ \\
\hline $\mathrm{x}_{2}{ }^{2}$ & 0.0501 & 1 & 40.9 & 0.0001 \\
\hline $\mathrm{x}_{3}{ }^{2}$ & 0.00639 & 1 & 5.22 & 0.0454 \\
\hline $\mathrm{X}_{1} \mathrm{X}_{2}$ & 0.0109 & 1 & 8.90 & 0.0137 \\
\hline $\mathrm{X} 1 \mathrm{X} 3$ & 0.00126 & 1 & 1.03 & 0.334 \\
\hline $\mathrm{x}_{2} \mathrm{X}_{3}$ & 0.00248 & $\begin{array}{l}1 \\
1\end{array}$ & 2.02 & 0.185 \\
\hline $\begin{array}{l}\text { Artık } \\
\text { Model } \\
\text { uygunsuzluğ }\end{array}$ & 0.0122 & 0 & & \\
\hline $\mathrm{u}$ & 0.00833 & 5 & 2.13 & 0.213 \\
\hline Hata & 0.00391 & $\begin{array}{l}5 \\
1\end{array}$ & & \\
\hline Toplam & 0.446 & 9 & & \\
\hline \multicolumn{5}{|l|}{ Kuruma Hizı } \\
\hline Faktör & $\begin{array}{l}\text { Kareler } \\
\text { Toplam1 }\end{array}$ & df & $\begin{array}{l}\mathrm{F} \\
\text { Değeri } \\
\end{array}$ & $\begin{array}{l}\text { p-değeri } \\
\text { Olasılık } \\
>\mathrm{F}\end{array}$ \\
\hline Model & $\begin{array}{l}0.00014 \\
8 \\
3.88 \mathrm{E}-\end{array}$ & 3 & $\begin{array}{l}4.95 \mathrm{E}- \\
005 \\
3.88 \mathrm{E}-\end{array}$ & $\begin{array}{l}< \\
0.0001\end{array}$ \\
\hline $\mathrm{x}_{1}$ & $\begin{array}{l}007 \\
0.00010\end{array}$ & 1 & $\begin{array}{l}007 \\
0.00010\end{array}$ & $\begin{array}{l}0.686 \\
<\end{array}$ \\
\hline $\mathrm{x}_{2}$ & $\begin{array}{l}5 \\
4.36 \mathrm{E}-\end{array}$ & 1 & $\begin{array}{l}5 \\
4.36 \mathrm{E}-\end{array}$ & $\begin{array}{l}0.0001 \\
0.00049\end{array}$ \\
\hline $\mathrm{x}_{3}$ & $\begin{array}{l}005 \\
3.68 \mathrm{E}-\end{array}$ & $\begin{array}{l}1 \\
1\end{array}$ & $\begin{array}{l}005 \\
2.30 \mathrm{E}-\end{array}$ & 3 \\
\hline $\begin{array}{l}\text { Artık } \\
\text { Model }\end{array}$ & 005 & 6 & 006 & \\
\hline $\begin{array}{l}\text { uygunsuzluğ } \\
\text { u }\end{array}$ & $\begin{array}{l}3.47 \mathrm{E}- \\
005\end{array}$ & $\begin{array}{l}1 \\
1\end{array}$ & $\begin{array}{l}3.15 \mathrm{E}- \\
006 \\
415 \mathrm{E}\end{array}$ & 0.0182 \\
\hline Hata & $\begin{array}{l}2.0 / \mathrm{E}- \\
006 \\
0.00018\end{array}$ & $\begin{array}{l}5 \\
1\end{array}$ & $\begin{array}{l}4.15 E^{-} \\
007\end{array}$ & \\
\hline Toplam & 5 & 9 & & \\
\hline
\end{tabular}

\section{Optimum Kurutma Koşullarının Belirlenmesi}

Yanıt yüzey yönteminde yer alan giriş değişkenleri ve yanıtlar arasında uygun bir matematiksel bağıntı kurulmuş ve bu model kullanılarak optimizasyon yapılmıştır. Kurutma koşulları ve yanıtlar arasındaki ilişkiyi tanımlayan matematiksel model aşağıda verilmiştir ve değişkenlerin kod değerleri bu denkleme göre belirlenmiştir. i ve j'nin doğrusal ve ikinci dereceden katsayılar olduğu yerde; $b$ bir regresyon katsayısinı. $\mathrm{k}$ deney tasarımındaki optimize edilen faktörleri ve e ise rastgele bir hatayı tanımlamaktadır.

$$
y=b_{0}+\sum_{i=1}^{k} b_{i} X_{i}+\sum_{i=1}^{k} b_{i j} X_{i}^{2}+\sum_{i j<j}^{k} \sum_{j}^{k} b_{i j} X_{i} X_{j}+e
$$

Tablo 2 de verilen koşullarda yapılan deneyler sonucunda alınan yanıtlara göre kurutma koşulları ve yanıtlar arasındaki ilişkiyi tanımlayan matematiksel model oluşturulmuş ve aşağıda verilmiştir.

$\mathrm{Y}_{\mathrm{WL}}=0.550-0.000989 \mathrm{X}_{1}+0.146 \mathrm{X}_{2}-0.0547$

$\mathrm{X}_{3}+0.00437 \mathrm{X}_{1}{ }^{2}-0.0495 \mathrm{X}_{2}^{2}+0.00853 \mathrm{X}_{3}^{2}-0.0235 \mathrm{X}_{1}$

$\mathrm{X}_{2}+0.000679 \mathrm{X}_{1} \mathrm{X}_{3}-0.0122 \mathrm{X}_{2} \mathrm{X}_{3}$

$\mathrm{Y}_{\mathrm{DR}}=0.0227+0.000169 \mathrm{X}_{1}-0.00277 \mathrm{X}_{2}$

$+0.00179 \mathrm{X}_{3}+0.018 \mathrm{X}_{1} \mathrm{X}_{2}+0.013 \mathrm{X}_{1} \mathrm{X}_{3}-0.020 \mathrm{X}_{2} \mathrm{X}_{3}(7)$

$\mathrm{Y}_{\mathrm{SR}}=0.566-0.00164 \mathrm{X}_{1}+0.148 \mathrm{X}_{2}-0.0631 \mathrm{X}_{3}$

$+0.015 \mathrm{X}_{1}^{2}-0.0589 \mathrm{X}_{2}^{2}+0.0211 \mathrm{X}_{3}^{2}-0.0369 \mathrm{X}_{1} \mathrm{X}_{2}$ $+0.0125 \mathrm{X}_{1} \mathrm{X}_{3}-0.0176 \mathrm{X}_{2} \mathrm{X}_{3}(\mathbf{8})$

Yukarıda program tarafindan belirlenen 6,7 ve 8 eşitlikleri kullanarak kurutma koşullarının optimum seviyeleri belirlenmiştir. Eşitlikler kolay türevi alınabilen denklemler olduğu için her bir etkene göre birinci türev alınıp yanıt sıfira eşitlenerek (analitik yöntem) katsayılar matrisi oluşturulmuştur. $\mathrm{Bu}$ katsayılar matrisi MATLAB da çözülerek her bir değişken için optimum seviyeler aşağıdaki Tablo 5'deki gibi belirlenmiştir. 
Tablo 5.Optimium kurutma koşulları

\begin{tabular}{|l|c|c|c|}
\hline Yanıtlar & $\mathrm{X}_{1}(\mathrm{~g})$ & $\mathrm{X}_{2}(\mathrm{dk})$ & $\mathrm{X}_{3}(\mathrm{~mm})$ \\
\hline Nem kayb1 & 105.720 & 159.042 & 6.667 \\
\hline Kurutma Hızı & 100.001 & 218.120 & 6.480 \\
\hline Büzülme Oranı & 92.860 & 274.800 & 6.504 \\
\hline
\end{tabular}

Maksimum su kaybı için kurutma parametrelerinin optimum seviyeleri tepsiye yüklenen taze elma dilimlerinin kütlesi için 92.860-105.720 g, kurutma süresi için $159.042-274.800 \mathrm{dk}$ ve elma dilim kalınlığı için 6.480-6.667 mm aralığında olduğu belirlenmiştir. Dilim kalınlığının azalması ve kurutma süresinin artması ile elma diliminden nem kayb1 ve büzülme oranı artmıştır.

\section{Sonuç}

Mersin'de hava sıcaklığı diğer illerimize göre yüksek olmasına karşın hava nemi de yüksektir. Bu durum, kurutma ortamı için sorun oluşturmaktadır. Ancak güneş enerjili kurutucu odasındaki hava sıcaklığı güneş altındakinden daha yüksek ve hava nemi de daha az olduğundan Mersin de kullanımı ile kurutmadaki bu sorun çözüme kavuşabilir. Ayrıca kurutma işleminin parametreleri proses tasarımlarını ve işlemi verimli hale getirmek amaciyla optimize edilmesi güneş enerjili kurutucuların kullanımının sanayide uygulanabilirliği arttırılarak yaygınlaşması sağlanabilir. Bu çalışmada optimizasyon yöntemi olarak kullanılan RSM ile 20 gibi az sayıda deneyle optimum sonuca ulaşılmıştır. Deney sonuçlarıyla uyumlu bir matematiksel model elde edilmiş ve bu modelin ANOVA istatistiksel analizi yapılmıştır. Nem kaybı, büzülme oranı ve kurutma hızı üzerine tepsiye yüklenen taze elma dilim miktarının etkisinin olmadığı, dilim kalınlığının ve kurutma süresinin etkisi olduğu bulunmuştur.

\section{Kaynaklar}

Aboud, A. (2013) Drying Characteristic of Apple Slices Undertaken the Effect of Passive Shelf Solar Dryer and Open Sun Drying. Pakistan Journal of Nutrition 12 (3), 250-254.
Aktas, M., Ceylan, İ., Dogan, H. (2006). Günes Enerjili Kurutma Fırınında Elma Kurutmas1. Politeknik Dergisi 289-294.

Darıcı, S., Şen, S. (2012) Kivi Meyvesinin Kurutulmasinda Kurutma Havasi Hizının Kurumaya Etkisinin İncelenmesi. Tesisat Mühendisliği Dergisi 20 (130): 51- 58.

Eren, İ., Ertekin, F. K. (2007) Optimization of osmotic dehydration of potato using response surface methodology. Journal of Food Engineering 79: 344-352.

Eren, İ. (2004) Patateslerin osmotic dehidrasyonunun response surface metodu kullanılarak optimizasyonu. Yüksek Lisans Tezi. Ege Üniversitesi.

Ertekin, F. K., Sultanoğlu, M. (2000) Modelling of mass transfer during osmotic dehydration of apples. Journal of Food Engineering 46(4), 243-250.

Ertekin, C., Yaldız, O. (1998) Bazı Sebze. Meyve ve Baharatlı Bitkilerin Kurutulma Yöntemleri ve kullanılan Güneş Enerjili Kurutucular. Tarımsal Mekanizasyon 18. Ulusal Kongresi. Tekirdağ. 673-693 s.

Mitra, P., Meda, V. (2009) Optimization of microwave-vacuum drying parameters of saskatoon berries using response surface methodology. Drying Technology. 27: 1089-1096.

Oztürk, H. (2008) Yenilenebilir Enerji Kaynaklart ve Kullanımı. Ankara.

Tüfekçi, S. (2014) Ultrases Ön İşleminin Bamya ve Elma Örneklerinin Kurutma Performansları Üzerine Etkisi. Yüksek Lisans Tezi. Pamukkale Üniversitesi. Denizli

Yıldız, Z., Gökayaz, L. (2018) Çok Raflı Günes Enerjili Kurutucuda Elma Kurutulmasi. 3rd International Mediterranean Science And Engineering Congress IMSEC 2018. Adana.

Yıldız, Z., Sarımeşeli, A. (2015) Optimization of Osmotic Dehydration of Organic Red Pepper 
Güneş Enerjili Kurutucuda Kurutulan Elma Dilimlerinin Kurutma Koşullarının RSM ile Optimizasyonu

Using Response Surface

Methodology, International Journal

of Engineering \& Applied Sciences (IJEAS). Vol.7. Issue 419-33.

Y1ldı, Z., (2017) Osmotic dehydration of anchovy fillets in salt solution: optimization by using statistical experimental design. Iranian Journal of Fisheries Sciences, 16 (4): 1187-1203. 